\title{
OBSERVACIONES SOBRE ALGUNAS OBRAS DE PABLO VERONÉS Y DE SUS SEGUIDORES EN ESPAÑA (CARLETTO, BENEDETTO Y GABRIELE CALIARI)*
}

\author{
POR \\ JOSÉ MARÍA RUIZ MANERO \\ Dr. en Historia del Arte
}

En este artículo se estudian tanto las obras conocidas en España de Carletto, Benedetto y Gabriele Caliari, como otras que se les atribuyen por primera vez.

Palabras clave: Carletto Caliari. Benedetto Caliari. Gabriele Caliari. Museo del Prado. El Escorial.

The author studies the known works in Spain by Carletto, Benedetto and Gabriele Caliari, as well as others attributed to them for the first time.

Key words: Carletto Caliari. Benedetto Caliari. Gabriele Caliari. Prado Museum. El Escorial.

En la Venecia del Renacimiento Pablo Veronés fue capaz de establecer un amplio taller, compuesto principalmente por miembros de su familia, que después de su muerte perpetuó en gran medida su estilo. Aun después de desaparecido el maestro, la deuda tan grande que se percibe en las obras de sus discípulos ha hecho que se le hayan atribuido obras que en realidad pertenecen a éstos. Asimismo, el hecho de que realizaran pinturas en colaboración y que las firmaran como "Haeredes Pauli" no ha facilitado la reconstrucción de la personalidad artística de cada uno de ellos. En el siglo XX se debe en gran parte a Crosato Larcher el haber logrado definir el estilo de los pintores del círculo de Veronés, los cuales, si bien poseen un indudable aire de familia que dificulta su identificación, no dejan por ello de tener cada uno algunos propios rasgos privativos.

De los seguidores de Pablo es sin duda su hijo Carletto el pintor con un estilo más propio, estilo que se forjó elaborando lo aprendido en el taller de su padre y en el de los Bassano. Nos informa Ridolfi que, aunque el primer maestro de Carletto fue ciertamente su padre, éste lo envió a la escuela de Bassano. Boschini y la historiografía posterior precisaron que Carletto fue discípulo de

\footnotetext{
*Este artículo es la tercera y última parte de los artículos "Observaciones sobre algunas obras de Pablo Veronés y de sus seguidores en España" (I. Pablo Veronés)", publicado en Archivo Español de Arte, T. LXXV, 2002, n² 297, pp. 5-21, y "Observaciones sobre algunas obras de Pablo Veronés y de sus seguidores en España" (Alvise Benfatto del Friso, Michele Parrasio)", publicado en Archivo Español de Arte, T. LXXVIII, 2005, nº 309, pp. 45-58.
} 
Jacopo Bassano. Fiocco y, posteriormente, Crosato Larcher pensaron que resultaba más probable que lo hubiera sido de los hijos de éste: Francesco y quizás Leandro, ya que, entre otras cosas, además de que éstos se habían trasladado a Venecia, en la obra del hijo de Pablo Veronés no encontramos el luminismo y sentido dramático de Jacopo, sino más bien el gusto por lo anecdótico y lo naturalista típico sobre todo de Francesco. Además, como argumenta la misma Crosato, si se considera a éste último como el maestro del joven Caliari, se puede en parte explicar el origen del preciosismo flamenco de Carletto, si se tiene en cuenta la influencia que ejerció Paolo Fiammingo sobre dicho Bassano ${ }^{1}$.

Varias son las obras que conserva el Museo del Prado de dicho pintor. En primer lugar, una "Santa Águeda" (L. 115 x $86 \mathrm{cms}$ ) (Fig. 1) -firmada "CARLO. VER . F", en la mesa colocada en primer término-2 ${ }^{2}$ que fue entregada por Felipe II a El Escorial el 8 de julio de $1593^{3}$ y que hasta el siglo XIX permaneció en el Monasterio 4 .

Una habitación pobremente amueblada constituye el entorno que rodea a la santa, a la que se le ha torturado cortándole el pecho y que en el momento de la representación es confortada por

${ }^{1}$ Crosato Larcher, L. "Per Carletto Caliari”, Arte Veneta, Venecia, Año XXI, 1967, p. 108. Sobre Carletto véase, además, Larcher Crosato, L., "La bottega di Paolo Veronese", en Nuovi studi su Paolo Veronese, Venecia, 1990, pp. 263-264.

${ }^{2}$ Museo del Prado. Inventario General de Pinturas. I La Colección Real, Madrid, 1990, p. 218, $\mathrm{n}^{\circ} 777$ (inv. act. $\mathrm{n}^{\circ}$ 480). Tanto en el inventario de 1857 como en el inventario actual del Prado y en los catálogos en los que se menciona siempre se ha considerado obra de Carletto Caliari.

3"Otro lienço al ollio de Sancta Agueda, con vn pecho cortado y vn angel con vna palma en la mano: tiene de alto vna bara y çinco dozabos y de ancho vna bara y un dozabo (traducido a centímetros 118 x 90,4), en su marco, con molduras doradas y negras" (Zarco Cuevas, Fray J., "Inventario de las alhajas, relicarios, estatuas, pinturas, tapices y otros objetos de valor y curiosidad donados por el rey don Felipe II al Monasterio de El Escorial. Años 1571 a 1598.”, Boletín de la Real Academia de la Historia, Madrid, tomo XCVII, 1930, p. 76).

${ }^{4}$ Pocos años después de entregada por Felipe II la cita el padre Sigüenza en el claustro de la enfermería: " una Santa Agueda, cortado el pecho; parece que viene de cosa suya (se refiere a Pablo Veronés); dicen que es de su hijo; creo hay alguna otra que no me acuerdo bien." (Sigüenza, Fray José de, La Fundación del Monasterio de El Escorial, [1605], Madrid, 1986, parte segunda, discurso XVII, p. 373). En 1657 el padre Francisco de los Santos la menciona, siempre en el Monasterio y como obra de "Carlos Veronès", sin especificar su ubicación exacta (Descripcion breve del Monasterio de S. Lorenzo El Real del Escorial, Madrid, 1657, fol. 56.). El mismo padre Santos en su edición de 1667 la cita en la Iglesia Vieja (Idem, idem, edición de 1667, fol. 60), en donde también figura en una relación anónima del siglo XVII sobre los cuadros de El Escorial (Andrés, G. de, "Relación anónima del siglo XVII sobre los cuadros del Escorial", Archivo Español de Arte, Madrid, n 173, 1971, pp. 62-63.). Ya en el siglo XVIII, siempre a nombre de Carletto, la siguen describiendo en la misma Iglesia Andrés Ximénez (Descripción del Real Monasterio de San Lorenzo del Escorial, Madrid, 1764, fols. 115-116), el autor de una relación histórica de las pinturas de El Escorial por su orden riguroso de colocación hecha en 1776 (Vega, A., "Relación histórica de las pinturas de El Escorial por su orden riguroso de colocación hecha en 1776", Documentos para la Historia del Monasterio de San Lorenzo, El Escorial, T. V, 1962, p. 261) y Ponz, A. (Viaje de España, Madrid, 1788, T. II, Carta IV, nº 67 (edic. 1988, Vol. I, p. 403)). El 1 de noviembre de 1809, fue trasladada por Quilliet de El Escorial a Madrid: "VERONÉS. Santa Agueda" (en el cajón n 14) (Hempel Lipschutz, I., "El despojo de obras de arte en España durante la Guerra de la Independencia", Arte Español, Madrid, tomo XXIII, 1961, p. 239) y el 14 de mayo de 1813 del exconvento del Rosario a la Academia de San Fernando: "N. 279. Vn quadro de 5 palmos y medio de alto por 4 y 2 dedos de ancho (traducido a centímetros 115,5 x 87,6). Representa á Sta. Agueda confortándola un ángel después del martirio. Carlos Veronés." (V.V., "Manuel Napoli y la colección de cuadros del exconvento del Rosario", Revista de Archivos, Bibliotecas y Museos, Madrid, año IX, número 2, febrero de 1905, p. 156.). Sabemos por Fray Damián Bermejo que en 1820 se encontraba en la sacristía del Monasterio (Descripción artística del Real Monasterio de San Lorenzo del Escorial y sus preciosidades después de la invasión de los franceses, Madrid, 1820, p. 85), de donde vendría al Museo del Prado en 1839 (cf. Museo del Prado. Catálogo de las pinturas, Madrid, 1985, p. 759). Poleró lo menciona entre los cuadros procedentes de El Escorial que entonces se hallaban en el Real Museo: "777 Santa Águeda (C. Veronés)" (Catálogo de los cuadros del Real Monasterio de San Lorenzo, llamado del Escorial, en el que se comprenden los del Real Palacio, Casino del Príncipe y Capilla de la Fresnada, Madrid, 1857, p. 183). 
un ángel. Crosato Larcher ${ }^{5}$ sitúa su ejecución -por supuesto antes de 1593 - tras una serie de obras de inspiración veronesiana de la plena madurez de Carletto, destacando que supone un cambio estilístico respecto a éstas. Alude al interés que demuestra por el juego de sombras y "sfumati", y a la nueva gracia que infunde a los rostros. Igualmente, menciona el gusto flamenco que se trasluce de la ambientación de la escena. Por su parte, Berenson (nota manuscrita, que recoge su opinión, en el archivo fotográfico del Prado) notó en la misma una clara influencia de Tintoretto. En cambio, Heineman (misma fuente que Berenson), en visita a los fondos del Museo el 17 de octubre de 1973, propuso a Francesco Montemezzano como su autor.

Sin duda debe tratarse de obra de avanzada la carrera de Carletto, ya que muestra una interiorización del lenguaje aprendido en el taller de su padre y de los Bassano que la coloca cerca temporalmente, como piensa Crosato Larcher, de una serie de pinturas, consideradas tardías por la misma historiadora, en las que el autor hace una personal síntesis de lo aprendido con sus maestros. Aunque, por una parte, los tipos de la santa y del ángel tengan su origen en Pablo Veronés, así como el colorido, si bien algo más mortecino, y , por otra, el gusto por la representación de los objetos de la vida cotidiana, la utilización del "sfumato" y el juego de las sombras recuerden al mundo de los Bassano, no tiene nuestra pintura ni la magnificencia de colorido ni el esplendor decorativo de las obras de Pablo Veronés, ni tampoco la inmediatez y carácter marcadamente popular de las de los Bassano. Logra Carletto con esta pintura, sin perder una cierta elegancia y distinción en las actitudes y en la composición, hacer descender el elevado mundo de su padre a la tierra. Por el contrario, esa misma herencia paterna le impide realizar una escena de marcado carácter popular. Su pincelada en comparación con la de Pablo resulta más serena y caligráfica, menos vibrante e intensa. Cabe destacar, asimismo, que su colorido, algo discreto y silencioso piénsese en el rosa pálido de la túnica del ángel, el rosa con reflejos amarillentos de la de la santa o el marrón verduzco de su manto-, sirve para acentuar la dulce melancolía que se desprende del cuadro.

Cuenta el Museu d'Art de Girona con un "San Jerónimo" (L. 132 x 95 cms) ${ }^{6}$ (fig. 2), depósito del Prado ${ }^{7}$, que ha sido objeto de múltiples atribuciones ${ }^{8}$ y que en realidad se trata de una copia, con ligeras variaciones, de la pintura del mismo asunto conservada en la National Gallery de Washington (L. 125 x $98 \mathrm{cms}$ ), pintura que gran parte de la crítica atribuye a Pablo Veronés ${ }^{9}$. Las diferencias de composición más importantes entre ambas son las siguientes: el león de Washington se

\footnotetext{
${ }^{5}$ Crosato Larcher, L., op.cit. (nota 1), p. 114. Véanse, también, Angulo Íñiguez, D. (Museo del Prado. Pintura italiana anterior a 1600, Madrid, 1979, p. 205), Ruiz Gómez, L. (Catálogo de Pintura Veneciana histórica en el Real Monasterio de El Escorial, Madrid, 1991, pp. 147-148), quien ofrece un apurado estudio de su procedencia, Checa, F. (Tiziano y la monarquía hispánica, Madrid, 1994, p. 293) y Falomir, M. (autor de la ficha de De Tiziano a Bassano. Maestros venecianos del Museo del Prado, cat. exp. (Barcelona, Museu Nacional d’Art de Catalunya), Barcelona, 1997, pp. 154-157).

${ }^{6}$ Medidas facilitadas por el Museu d'Art de Girona en carta fechada el 11 de noviembre de 1997.

${ }^{7}$ Museo del Prado. Inventario General de Pinturas. I La Colección Real, Madrid, 1990, p. 146, $\mathrm{n}^{\circ} 492$ (inv. act. $\mathrm{n}^{\circ}$ 5.135) (Las medidas que facilita están equivocadas: 1,01 x 0,70 ms. En la ficha del inventario de 1857 figura como obra de "Tiziano" y en la ficha del inventario actualizado como "Anónimo").

${ }^{8}$ Considerada obra de Tiziano por Bermejo (op. cit. (nota 4)., p. 200), Poleró (op. cit. (nota 4), p. 182 (n 492)), Girbal, E. C. (Catálogo de los cuadros del Museo Provincial de Gerona, Girona, 1882, p. 18 (n 35)) y en Primera mostra del Patrimoni artistic de la Diputaciò de Girona, cat. exp., Girona, 1979 ( $\mathrm{n}^{\circ}$ 81) ; por su parte, Pla Cargol, J. (Catàleg de les obres de Pintura i Escultura existents en el Museu Provincial de Girona, Girona, 1932, p. 16 (n 35$)$ ) informa que se ha atribuido a la escuela veneciana, a Tiziano, a Bassano y recientemente a Moretto de Brescia; por último en "'El Prado disperso": Cuadros depositados en Gerona", Boletín del Museo del Prado, t. XII, n 30, 1991, p. 94 figura como "Anónimo Español del siglo XVII".

9 cf. Pignatti, T. y Pedrocco, F., Veronese. L'opera completa, Milán, tomo I, 1995, pp. 266-267.
} 
encuentra enfrente de las patas de la mesa y el de Gerona detrás; sobre ésta, en el cuadro americano, descansan, además del libro y el crucifijo, una calavera y un reloj de arena, mientras que en el nuestro ha desaparecido el reloj y se ha sustituido la calavera por un tintero. Aunque sus composiciones sean muy similares, resultan muy distintas en cuanto a su ejecución y a la forma de caracterizar al santo, coincidiendo respectivamente con los estilos de Pablo y Carletto. En el cuadro de Washington se representa a San Jerónimo con un marcado aspecto popular, aunque algo idealizado, en cambio en el de Gerona se acentúa su carácter plebeyo haciendo patente la influencia que Carletto recibió durante su estancia en el taller de los Bassano. Mientras aquél muestra una pincelada viva y vibrante y un aspecto general grumoso y fluido, en éste se observa una mayor tendencia a definir las formas y una manera de manejar el pincel más lineal y gráfica. Frente al paisaje evanescente y deshecho del cuadro americano, sorprende el preciosismo y minuciosidad, de clara raíz flamenca, con el que está tratado el del nuestro. Además, existe en éste un claro deseo de acentuar las sombras, lo que produce un cierto claroscuro que asimismo recuerda a los Bassano. Por su evidente relación con el mundo de estos últimos, cabría fecharlo en fecha temprana, es decir por los mismos años en que Carletto realizó los cuatro cuadros sobre Adán y Eva que se conservan en los Uffizi de Florencia ${ }^{10}$.

Se sabe que estuvo en El Escorial y que corresponde al cuadro que Bermejo menciona en la Sala Vicarial: "10. En el nicho: San Gerónimo penitente en el desierto, figura algo menor del tamaño natural, por idem (ser refiere a Ticiano)" y que Poleró cita entre los cuadros procedentes de El Escorial que entonces se hallaban en el Real Museo: "492 San Gerónimo (Tiziano)"11. Todo hace suponer que se trate del mencionado por el Padre Sigüenza en el aula del convento: “... encima de la misma cátedra está un San Jerónimo a la penitencia, de harto buen relieve y colorido, aunque otros dicen que no es suyo (de Pablo Veronés, se entiende), sino de su hijo."12. A su vez bien pudiera ser el siguiente entregado por Felipe II a El Escorial el 8 de julio de 1593 -fecha en la que, no olvidemos, dona asimismo la "Santa Agueda" también de Carletto, hoy en el Museo del Prado, que curiosamente también estaba enmarcado "con molduras doradas y negras"-: "Otro lienço al ollio de Sanct Hierónimo en la penitencia arrimado al tronco de vn árbol con vn Christo en la mano yzquierda puesto sobre vn libro y vna piedra en la derecha; tiene de alto vna bara y dos terçias y de ancho vna bara y vna terçia ( traducido a centímetros 139,1 x 111,3), en marco, con molduras doradas y negras" 13 . Desgraciadamente en las publicaciones e inventarios posteriores no ha sido posible identificar ninguna segura referencia al mismo ${ }^{14}$. En 1657 el padre de los Santos cita en su lugar: "vn Eccehomo del Ticiano, marauilloso."15.

Siempre de Carletto, también depósito del Prado, en el Museo de Pontevedra se conserva un cuadro del "Juicio de Paris"16 (Lienzo 119 x 135 cms) (fig. 3) que en todos los catálogos en

10 Véase Crosato Larcher, op.cit. (nota 1), p. 109-110.

11 Bermejo, op.cit. (nota 4), p. 200. Poleró, op. cit. (nota 4), p. 182.

En su ficha del inventario de la Diputaciò Provincial de Girona se dice que detrás del cuadro en la parte superior izquierda de su marco tiene una etiqueta de papel en la que se lee: "Sn Jerónimo haciendo penitencia/ Cuadro procedente de la Real Casa de San Lorenzo/...estuvo colocado en la Sala Vicarial frente las ventanas al número 10 (número que le asigna Bermejo). Pintado por Tiziano".

12 Sigüenza, op. cit. (nota 4), p. 373.

13 Zarco Cuevas, op. cit. (nota 3), p. 79-80.

${ }^{14}$ Aunque las posibilidades sean escasas, no se puede descartar completamente que no sea la citada por el padre Santos (ediciones de 1667 y 1681) en la Capilla del Colegio del Monasterio de San Lorenzo: "En el Testero, sobre la Silla del Prior, està vn San Geronimo en la Penitencia, Quadro pequeño, que haze Frontispicio....” (op. cit. (nota 4), 1667, fol. $95 \mathrm{v}$ y op. cit. (nota 4), 1681, fol. $78 \mathrm{v}$ ).

15 op. cit. (nota 4), fol. $72 \mathrm{v}$.

16 Museo del Prado. Inventario General de Pinturas. I La Colección Real, Madrid, 1990, p. 497, n 1867 (inv. act. $\mathrm{n}^{\circ}$ 481) (en la ficha del inventario de 1857 figura como obra de Pablo Veronés y en la ficha del inventario actualizado como copia de Veronés). 
donde aparece se le atribuye, atribución que no parece ofrecer duda. También lo creyeron de su mano Bernard Berenson y Sánchez Cantón, quien nos informa de la opinión de Berenson ${ }^{17}$. En cuanto al momento de su ejecución, por las coincidencias de estilo que muestra con su "Angélica y Medoro" 18 cabría pensar que lo realizó en sus primeros años. En ambas obras el paisaje, de tratamiento muy similar, por su factura ligera y suelta y por el gusto por el detalle muestra un claro sabor flamenco. Por lo que respecta a la composición en las dos manifiesta su deuda con el mundo de su padre. En el "Juicio de Paris" debe a éste la manera de organizar la escena en forma de cascada colocando a Paris en un plano ligeramente superior al de las diosas ${ }^{19}$, así como los angelitos de extendidas alas que coronan a Afrodita ${ }^{20}$. Además, hace pensar que la realizara en fecha temprana la mezcla que presenta de elementos veronesianos, como los señalados, y bassanescos - piénsese en la figura en primer plano del perro hecho un ovillo que pertenece al repertorio de los Bassano o en la mencionada influencia flamenca presente en el paisaje, que puede tener su origen en Francesco Bassano- que no llega, sin embargo, a fundir en una síntesis personal como hará en sus creaciones más maduras. Por lo que respecta a su colorido resulta típico de Carletto, ya que se vale de una gama parecida a la de su padre, pero utilizando tonos más apaciguados y menos brillantes: piénsese en el rosa pálido del manto de Hera o en el azul algo grisáceo de la tela que cubre en parte a Afrodita. En la Buknell University de Lewisburg existe un cuadro del mismo asunto, cuya composición no muestra diferencias sustanciales con la del nuestro y cuya atribución divide a la crítica ${ }^{21}$. Por otra parte, en el Museo del Prado se conserva un dibujo, atribuido a Carletto y considerado preparatorio del lienzo del Prado por Sánchez Cantón ${ }^{22}$, que muestra con muy ligeras variaciones la composición estudiada.

En el inventario del Alcázar de 1666 se cita entre los cuadros de la "galeria baja del jardin de los emperadores": "700 -vara y media de largo y vara y quarta de alto (traducido a centímetros 104,5 x 125,25) del Juicio de Paris de mano de Paulo Verones 400 dus". Se sigue mencionando con las mismas medidas y siempre como obra de Pablo Veronés- ahora en las"Bóvedas (que llaman) del Tiziano", en los inventarios de dicho palacio de $1686{ }^{23}$ y de 1700 , en éste con el número $495^{24}$. En el siglo XVIII se conservó en el Palacio del Buen Retiro, ya que figura en los

Depositado por Real Orden de 8 de junio de 1929 (Orihuela, M., "El Prado disperso". Cuadros depositados en las provincias de La Coruña, Lugo, Orense y Pontevedra", Boletín del Museo del Prado, t. IX, números 25, 26, 27, 1988, pp. 140-141 (obra de Carletto Veronese)).

17 Sánchez Cantón, F. J., "El Juicio de Paris "de Carletto Veronese"”, El Museo de Pontevedra, entrega no 1, 1942, pp. 17-19. También Gaya Nuño, J.A. ("Notas al Catálogo del Museo del Prado" (El Prado disperso e inédito)", Boletín de la Sociedad Española de Excursiones, tomo LVIII, 1954, p. 116; e Historia y Guía de los Museos de España, Madrid, 1968, p. 651) lo menciona como obra de Carletto Veronese.

${ }_{18}$ Ridolfi dice que Carletto pintó, cuando apenas tenía 17 años, un cuadro de "Angelica e Medoro", cuadro que Crosato Larcher identificó acertadamente con una pintura de dicho asunto en la colección Barbieri de Pádua (op. cit. (nota 1), pp. 108-109).

${ }^{19}$ Forma de componer también presente, por ejemplo, en su "Ester coronada por Asuero" (Iglesia de San Sebastián, Venecia), en sus frescos "Imeneo entre Juno y Venus" y "La Fortuna, la Abundancia y la Fe" (Villa Barbaro, Maser), en "La Unión Feliz" (National Gallery, Londres) y, sin ir más lejos, en su "Cristo y el centurión" que se conserva en el Museo del Prado.

20 Véanse, por ejemplo, los presentes en la decoración de la "Stanza del cane" (Villa Barbaro, Maser), en el "Matrimonio místico de Santa Catalina" (Galleria dell’ Accademia, Venecia), en la "Visión de Santa Elena" (National Gallery, Londres).

${ }^{21}$ Véase Pignatti, T., Veronese. L'opera completa, Venecia, 1976, T. I, p. 188.

22 Sánchez Cantón, op. cit. (nota 17), p. 18 y lám. II.

${ }^{23}$ Bottineau, Y., "L'Alcazar de Madrid et l'inventaire de 1686. Aspects de la Cour d'Espagne au XVIIe siècle", Bulletin Hispanique, tomo LX , n 3, 1958, p. 323.

Sánchez Cantón (op.cit. (nota 17), p. 18) intuyó que pudiera tratarse del cuadro que se menciona en los inventarios de 1666 y 1686, aunque no citó textualmente los asientos correspondientes.

${ }^{24}$ Fernández Bayton, G., Inventarios Reales. Testamentaría del Rey Carlos II 1701-1703, Madrid, t. I, 1975, p. 67 


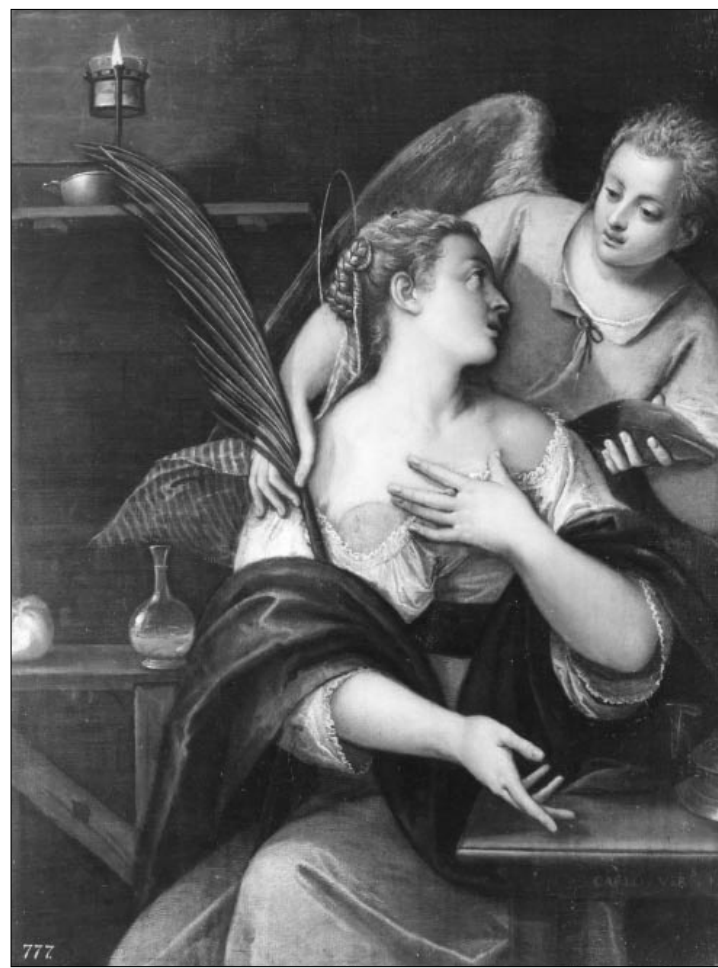

Fig. 1. Carletto Caliari: Santa Águeda. Madrid. Museo del Prado.

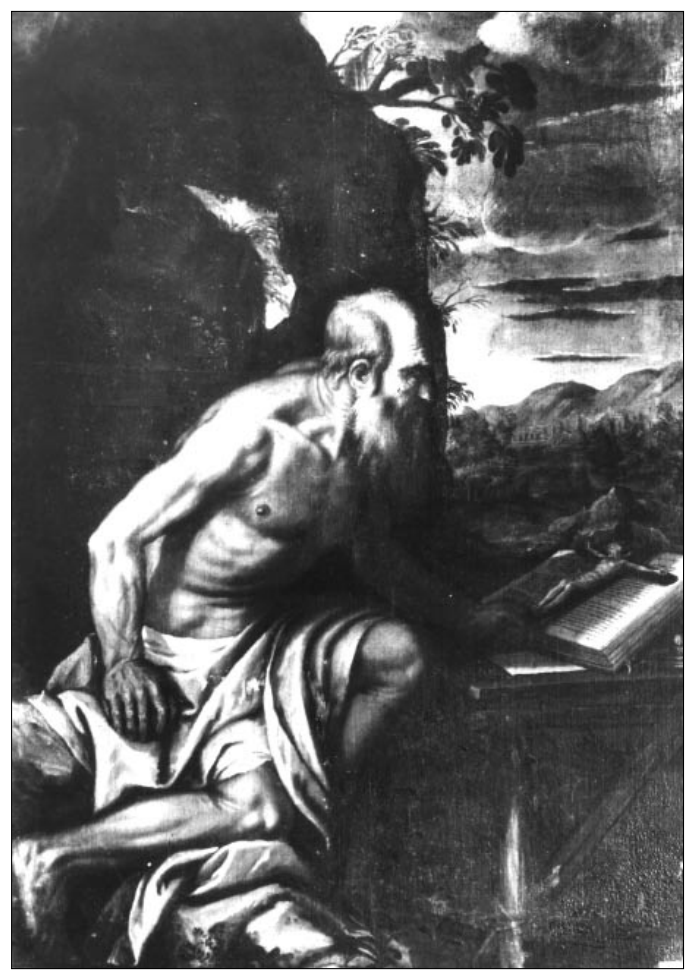

Fig. 2. Carletto Caliari: San Jerónimo. Madrid. Museo del Prado. Cuadro depositado en el Museu d'Art de Girona.

Fig. 3. Carletto Caliari: Juicio de Paris. Madrid. Museo del Prado. Cuadro depositado en el Museo de Pontevedra.

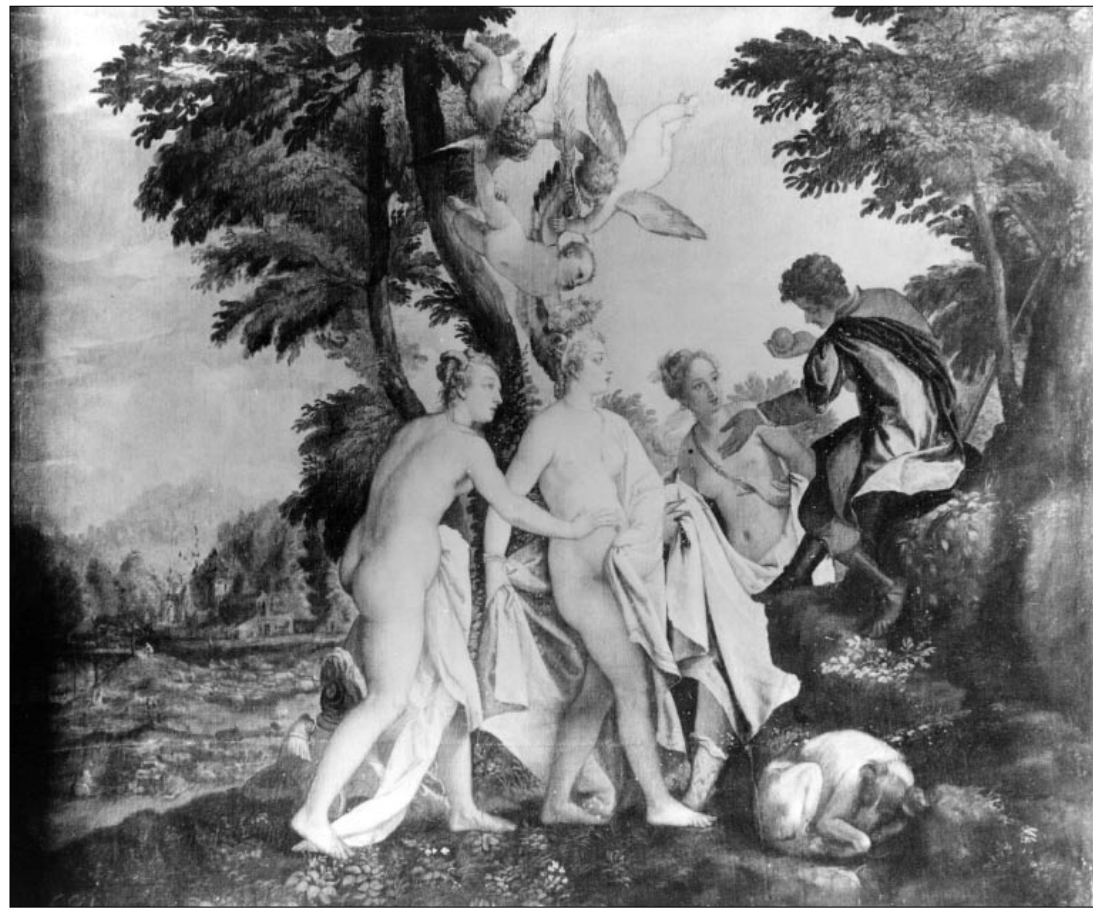

AEA, LXXIX, 313, ENERO-MARZO, 43-60, 2006, ISSN: 0004-0428 
inventarios de dicho palacio de 1772 (entre las "Pinturas también señaladas con la letra P colgadas en diferentes piezas de Palacio") : "608 El juicio de Paris de vara y media de largo y vara y quarta de caida (en centímetros 104,5 x 125,25) copia de Verones" y de 1789 (esta vez con medidas algo mayores debido a que posiblemente se agrandara): "681 (número que, en blanco, sigue conservando en su ángulo inferior izquierdo) Otra de Pablo Veronès con el Juicio de Paris: de vara y tercia de alto y v. ${ }^{\mathrm{a}} \mathrm{y}$ dos tecias de ancho (en centímetros $111,3 \mathrm{x} 139,1$ ) con marco dorado 1.000 " 25.

En cuanto a su estado de conservación puede considerarse satisfactorio. Sin embargo, da la impresión de que a la altura de las pantorrillas de las tres diosas se le cortó un pedazo, que posteriormente se recosió. En el siglo XVIII debió ensancharse y alargarse unos centímetros, lo que explicaría tanto su diferencia de tamaño en los inventarios del Retiro de 1772 y 1789 como que las medidas de la citada obra de Lewisburg (102 x 117) sean más semejantes a las mencionadas a propósito de la nuestra en el inventario de 1772 (104,5 x 125,25).

Se cuenta además con otras referencias en inventarios reales a cuadros de este asunto relacionados con Pablo Veronés:

En el inventario del palacio de la "Ribera" (Valladolid) de junio de 1607 figura en el "Primer aposento suviendo la escalera": "Mas vn lienço de bara y terçia enquadrado (en centímetros 111,3 x 111,3) Pintado En El vn juuicio de paris, buena copia de paulo barones."26. Se sigue citando en el mismo lugar en el inventario de 1615 de dicho palacio: "Vn lienzo de bara y tercia en quadrado, pintado en él vn Juicio de Paris, buena copia de Paulo Varonés." Todo parece indicar que corresponda a la siguiente inventariada en 1701 en el Palacio del Buen Retiro: "Una Pinttura de Uara y media Casi en quadro con Vn Pais del Juicio de Pari Copia de Pablo Berones Con marco negro tasada en doze doblones. 720" 27 , ya que, como se sabe por un memorial presentado por Alonso Cano, él mismo y Velázquez hicieron un viaje a Castilla la Vieja (Martí y Monsó con mucho criterio pensó que fueron a Valladolid) para elegir pinturas para el palacio del Buen Retiro 28 .

Asimismo, en el inventario del Real Palacio de Madrid de 1734 consta: "44- Otros dos de Pablo Veronés la vna del robo de Europa y la otra del Juicio de Paris de vara y tercia de alto y vara y media de ancho (en centímetros 111,3 x 125,25) con marcos dorados." Se vuelven a mencionar con el mismo número en los inventarios del Palacio del Buen Retiro de 1747 y del Nuevo Palacio de Madrid de 1772. Ponz los verá, siempre en este último palacio, en una de las piezas de paso desde los cuartos del rey y de la reina a la capilla ${ }^{29}$. En el inventario del mismo Palacio de 1789 figuran en la "Antecamara de las S.as Ynfantas": "44 y 44 Dos de vara y media en quadro: Jupiter transformado en Toro que lleba á Europa el primero: y el segundo el Juicio de Paris à quatro mil reales cada uno. Pablo Veronès .....8.000"30.

En el monasterio de El Escorial se conserva una "Sagrada Familia con San Juanito" (Lienzo 90 x 91,7 cms) (fig. 4), que Ruiz Gómez ${ }^{31}$ consideró obra de la esfera veronesiana y, acertadamente, puso de manifiesto que, al igual que una pintura del mismo asunto y composición del

\footnotetext{
25Fernández-Miranda, F., Inventarios Reales. Carlos III 1789-1790, Madrid, Vol. I, 1988, p. 309.

${ }^{26}$ Florit, J. M., "Inventario de los cuadros y otros objetos de Arte de la quinta real llamada "La Ribera" en Valladolid", Boletín de la Sociedad Española de Excursiones, tomo XIV, 1906, p. 155.

${ }^{27}$ Fernández Bayton, op. cit. (nota 24), t. II, p. 326.

${ }^{28}$ Martí y Monsó, J., "Diego Velázquez y Alonso Cano en Castilla la Vieja", Boletín de la Sociedad Castellana de Excursiones, año II, 1904, pp. 333-337 (fecha el viaje en 1635) y Wethey, H. E., Alonso Cano. Pintor, escultor y arquitecto, Madrid, 1983, p. 189 (lo sitúa hacia 1640).

${ }^{29}$ Ponz, op. cit. (nota 4), 1793 (tercera impresión), T. VI, nº 61 ( Madrid, 1988, Vol. II, p. 253).

${ }^{30}$ Fernández-Miranda, op. cit. (nota 25), Vol. I, p. 49.

${ }^{31}$ Ruiz Gómez -quien además informa de que se restauró en 1987-, op. cit. (nota 5), pp. 149-150.Véanse, también, AA. VV. (El Escorial. Octava maravilla, Madrid, 1987, fig. 187 (donde aparece reproducida a nombre de Pablo Veronés), Checa (op. cit. (nota 5), p. 294 (la cita a nombre de Carletto Caliari recogiendo la mención del padre Santos en su edición de 1657).
} 
Museo de Bellas Artes de Burdeos ${ }^{32}$, reproducía personajes y actitudes propios del maestro, especialmente "La Sagrada Familia con santa Bárbara y san Juanito" (Galleria degli Uffizi, Florencia). Al encontrarse en El Escorial y en Burdeos dos cuadros con la misma composición, ninguno de los cuales puede atribuirse a Pablo Veronés, y al resultar ésta última acorde con el estilo del maestro 33 , cabe pensar que debió existir una pintura o dibujo de éste que sirvió de modelo a aquéllos. Logra quien ideó esta composición, de rara elegancia y perfección, encajar la escena dentro de un esquema piramidal e inscribirlo, a su vez, en una refinada estructura circular que acoge en su interior al Divino Infante, centro de atención de las miradas de los demás personajes. Pero, si bien la forma de organizar la escena resulta propia de Pablo, la ejecución no parece corresponderle. Se diría que todo apunta, como ya supuso el Padre Santos en el siglo XVII, a que su ejecutor fuera su hijo Carletto quien, como se sabe, realizó dibujos a partir de creaciones suyas ${ }^{34}$ y copió, entre otras, su pintura hoy en los Uffizi citada por Ruiz Gómez ${ }^{35}$. $\mathrm{Su}$ colorido, algo tenue y apagado, carece de la extraordinaria fuerza expresiva de la paleta de Pablo Veronés y se asemeja al del cuadro de "Santa Águeda"de Carletto que conserva el Museo del Prado. El rosa pálido de la túnica de la Virgen, aunque más fuerte, recuerda al del vestido del Ángel del cuadro madrileño, asimismo el ocre amarillento del vestido de San José no es muy diferente del amarillo terroso del que se sirvió Carletto para las zonas iluminadas de la túnica de Santa Águeda. Además, también nos habla de Carletto la sutileza gráfica de la pincelada, que dibuja con trazo delgado y elegante los reflejos de las telas que cubren a los personajes y que tan alejada se encuentra de la apasionada y briosa forma con la que Pablo Veronés manejó el pincel.

En 1657 la cita el padre Santos en la Iglesia Antigua: "Otro ay de Carlos Veronès, hijo de Paulo, que es de nuestra Señora, y San Joseph, y el Niño dormido, cosa muy bien dispuesta, y executada. Este, y otros dos, que ay en otras Pieças, vno de Santa Agueda, con el pecho cortado, y vn Angel que la està curando; y otro de nuestra Señora, que tiene à Christo Señor nuestro, muerto en sus braços, al pie de la Cruz, con vnos Angeles à los lados ${ }^{36}$, muestran ser de vna misma mano,

\footnotetext{
32 Lienzo 105 x 92cms. Véase Pignatti, op. cit (nota 21), T. I, p. 172, nº A27 y T. II, fig. 740.

33 Además de la pintura señalada por Ruiz Gómez, véanse, al respecto, "La Sagrada Familia con San Juanito y San Jorge" (Ashmolean Museum, Oxford), "La Sagrada Familia con San Juanito" (Rijksmuseum, Amsterdam), "Sagrada Familia con San Juanito" (Iglesia de San Barnaba, Venecia), "La Sagrada Familia con Santa Catalina y San Juanito" (fresco en la "Stanza del cane", Villa Barbaro, Maser), "Madonna della Pappa" (fresco en la "Stanza della lucerna", Villa Barbaro, Maser). Todas obras que comparten con la composición de la nuestra un gusto por la representación íntima revestida de cierta majestuosidad, y una forma de disponer las figuras mediante ritmos amplios y acompasados. Pignatti y Pedrocco las sitúan entre 1555 y 1565 aproximadamente (op. cit. (nota 9), T. II, pp. 109-112, 174-228, 256-257), años en los que también pudiera haber ideado la composición de la nuestra que, andando el tiempo, copiaría Carletto.

34 Véase Cocke, R., Veronse Drawings. A catalogue raisonné, Londres, 1984, p. 336.

35 Copia conservada en el Museum of Art de Baltimore (Pignatti y Pedrocco, op. cit. (nota 9), T. I, p. 256).

36 Se conocen dos pinturas de "Cristo muerto, la Virgen y dos ángeles" que responden a la descripción del padre Santos. Una de ellas -publicada por F. Ingersoll-Smouse como obra de Pablo Veronés ( "Les Pieta de Véronèse", Gazette des Beaux Arts, año 68, tomo XIV, II semestre, 1926, p. 23-24. También la cita Pignatti, op. cit. (nota 21), T. I, p. 202), y que se encontraba en 1926 en una colección privada de París- pudiera ser, según la misma Ingersoll, la citada hacia 1689 en la colección de la reina Cristina de Suecia, quien, posteriormente, la legaría al rey de España. Identificación que no parece muy probable, ya que difícilmente se puede explicar, como desea la mencionada historiadora, que la no coincidencia ni del asunto (en el cuadro de la reina, además de Cristo, la Virgen y dos ángeles, presentes en el cuadro de París, se cita a dos querubines que lloran en la parte superior) ni de las medidas (el cuadro de la reina medía 208 x $176 \mathrm{cms}$ y el de París 115 x 90cms) se deba a que el de la reina se recortó en fecha posterior. Respecto a la otra (Lienzo 113 x $92 \mathrm{cms}$ ) -considerada por Ingersoll-Smouse copia de la anterior, y que figura en el Museo de Lille desde 1837 ( "L'oeuvre peint de Paul Véronèse en France", Gazette de Beaux Arts, año 70, tomo XVIII, II semestre, 1928, p. 44)pensó Pignatti ( op. cit (nota 21), T. I, p. 189) que quizá fuera obra de Benedetto Caliari y que tal vez pudiera identificarse bien con una pintura que en 1672 se encontraba en casa de la familia Moscardo de Venecia o bien con la que en
} 
y de estimable estudio"37. Al no mencionarse a San Juanito, cabría pensar con Ruiz Gómez que no existen suficientes elementos para identificarla ${ }^{38}$. Sin embargo, no cabe duda de que lo es, como se desprende del cotejo y combinación de las referencias que le dedican, ya en el siglo XVIII, por una parte, el padre Ximénez (1764) y Ponz (1788), y por otra, el autor de una "Relación histórica de las pinturas de El Escorial por su orden riguroso de colocación hecha en 1776"39. En 1820 se menciona en la Sala Vicarial: "4. (número que, escrito sobre un papelito pegado al cuadro, sigue conservando en su ángulo inferior derecho) En el nicho: La Virgen con el Niño dormido, san José y san Juan tambien Niño con una manzana, figuras menos de medio cuerpo, por Pablo Veronés." 40 . Por último, en el catálogo de Poleró figura con el número 101 (número que todavía sigue conservando en su ángulo inferior izquierdo), como obra de dicho pintor ${ }^{41}$.

El Museo del Prado cuenta con una copia de este cuadro debida a Juan Antonio de Frías y Escalante ( L. 54 x $46 \mathrm{cms})^{42}$ (fig. 5), copia que reproduce su composición con ligeras modificaciones, obsérvese en particular los Angeles añadidos en la parte superior. Pérez Sánchez, quien analizó la influencia de Pablo Veronés en Escalante, la reprodujo resaltando su directa vinculación veronesiana ${ }^{43}$. Por su parte, Urrea la consideró copia libre del cuadro conservado en El Escorial y que el padre Santos en su edición de 1657 cita en la Iglesia Antigua ${ }^{44}$.

1688 figuró en la venta de Lely. Ninguna de las dos identificaciones parece muy posible, ya que se sabe por IngersollSmouse (op.cit., t. II , 1926, p. 21) que en la pintura de la familia Moscardo se decía que había un solo ángel y en la de Lely que, además de Jesucristo, figuraban ángeles y otras figuras.

Debido a que no está probada la procedencia de las dos obras que se acaban de mencionar, pudiera ser que una de ellas fuera la que estuvo en El Escorial, en donde, por otra parte, no se vuelve a citar después de la francesada. Asimismo, A. E. Pérez Sánchez ("Veronese e la Spagna nel Seicento" en Nuovi studi su Paolo Veronese, Venecia, 1990, p. 98) puso de manifiesto la vinculación veronesiana de las versiones de Alonso Cano de "Cristo muerto sostenido por los ángeles". La presencia en El Escorial de un cuadro de este asunto relacionado con Veronés hace que no resulte descabellado pensar que Cano pudo tenerlo en cuenta a la hora de elaborar sus propias composiciones.

${ }^{37}$ Santos, op. cit.(nota 4), 1657, fol. 56 y 56v. Se sigue citando en el mismo lugar en una relación anónima del siglo XVII: "dos Nuestras Señoras, que están allí junto, son de Carlos Veronés" (Andrés (quien identifica a una de ellas con el cuadro de El Escorial), op.cit. (nota 4), p. 63).

${ }^{38}$ Según Ruiz Gómez, la primera referencia que, sin duda, se puede relacionar con nuestra pintura se la debemos a Bermejo (1820), quien la sitúa en la Sala Vicarial (op. cit. (nota 5), p. 150).

39 Dice el padre Ximénez: “y arriba sobre la Cornisa, uno de nuestra Señora al pie de la Cruz, con su Santísimo Hijo difunto sobre las rodillas, y dos Angeles á los lados, Original de Carlos Veronés; y otro Original del mismo, que es de nuestra Señora, San Joseph, y el Niño dormido, Pintura bien dispuesta, y executada.” (op. cit. (nota 4), fol. 114.) y Ponz: "una Nuestra Señora con Jesucristo difunto; bello cuadro, tenido por de Carlos Veronés, aunque parece de lo más excelente de su padre, Pablo; y de su misma escuela es el inmediato de San José y Nuestra Señora con el Niño dormido." (op. cit. (nota 4), 1788, T. II, Carta IV, n 63 (Madrid, 1988, Vol. 1, p. 402)). En la "Relación histórica de las pinturas de El Escorial por su orden riguroso de colocación hecha en 1776" se cita, siempre en la Iglesia vieja, aludiendo por primera vez a quien faltaba en las otras descripciones, es decir a San Juanito: "10. Nra. Sra., S. Josef, Niño dormído, S. Juán .... 11. Christo muerto, dos ángeles y la Virgen O (quiere decir original) Veronés" (Vega, op. cit. (nota 4), p. 260).

Por otra parte, si se admite que el cuadro estudiado corresponde al citado en la Iglesia Vieja, hay que rechazar la suposición de Vega de que pudiera identificarse con el siguiente citado en la misma relación en la Sacristía: "11. Nra. Sra.con el niño dormido OP (quiere decir original pequeño) P. (se refiere al autor del cuadro, que en este caso Vega piensa que se trata de Pablo Veronés)" (Vega, op. cit. (nota 4), p. 248).

40 Bermejo, op. cit. (nota 4), p. 198.

${ }^{41}$ Poleró, op. cit. (nota 4), p. 47 ( $\left.\mathrm{n}^{\circ} 101\right)$. Se encontraba entonces en la Sacristía , en donde, siempre como obra de Pablo, también la cita Rotondo, A. (Descripción de la Gran Basílica del Escorial, Madrid, 1861, p. 81).

42 Museo del Prado. Inventario General de Pinturas.I La Colección Real, Madrid, 1990, p. 68, $\mathrm{n}^{\circ} 185$ (inv. act. $\mathrm{n}^{\circ}$ 695) (figura como obra de Escalante, sin decirse que sea copia del cuadro de El Escorial).

43 Pérez Sánchez, op. cit.(nota 36), pp. 102-103 y fig. 80.

44 Pintores del Reinado de Felipe IV, cat. exp., (Vigo, Centro Cultural Caixa Vigo), Madrid, 1994, pp. 92-93. 
Fig. 4. Carletto Caliari: Sagrada Familia con San Juanito. El Escorial (Madrid). Monasterio (Copyright Patrimonio Nacional).

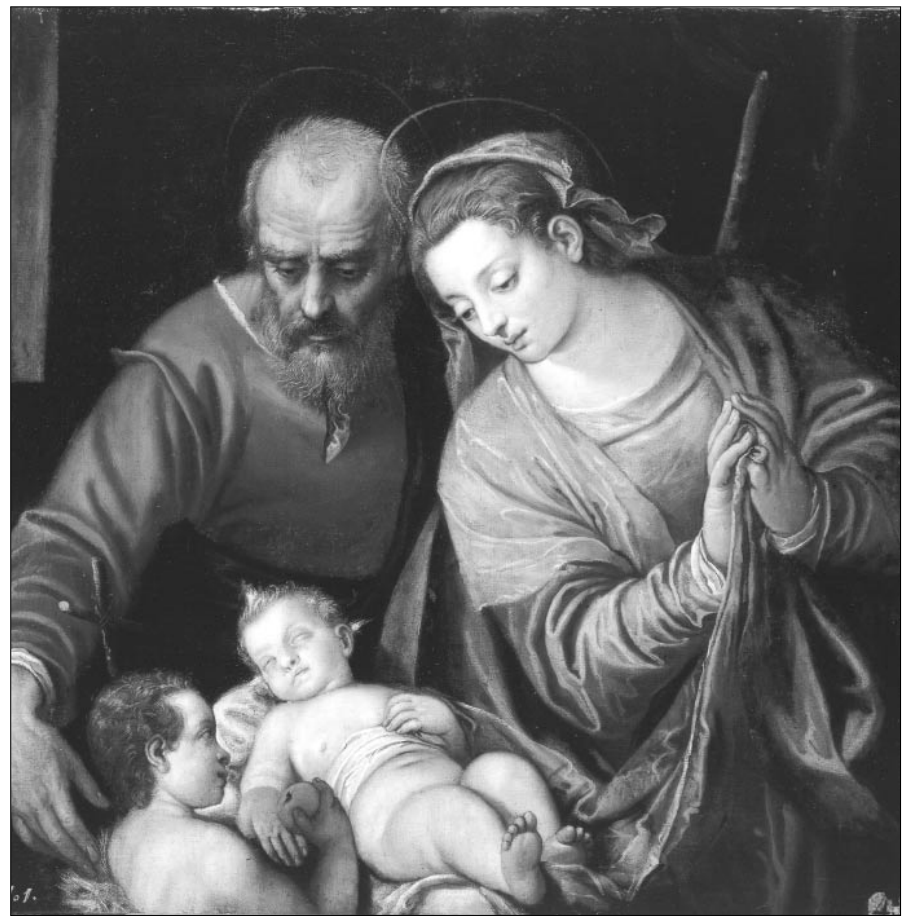

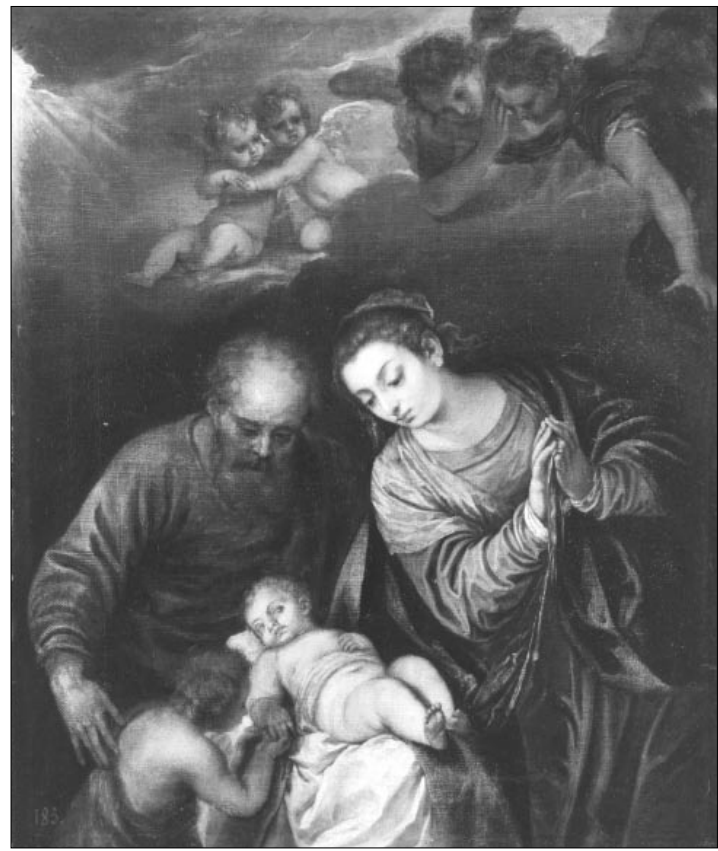

Fig. 5. Carletto Caliari (Copia de Juan Antonio de Frías y Escalante): Sagrada Familia con San Juanito. Madrid. Museo del Prado.

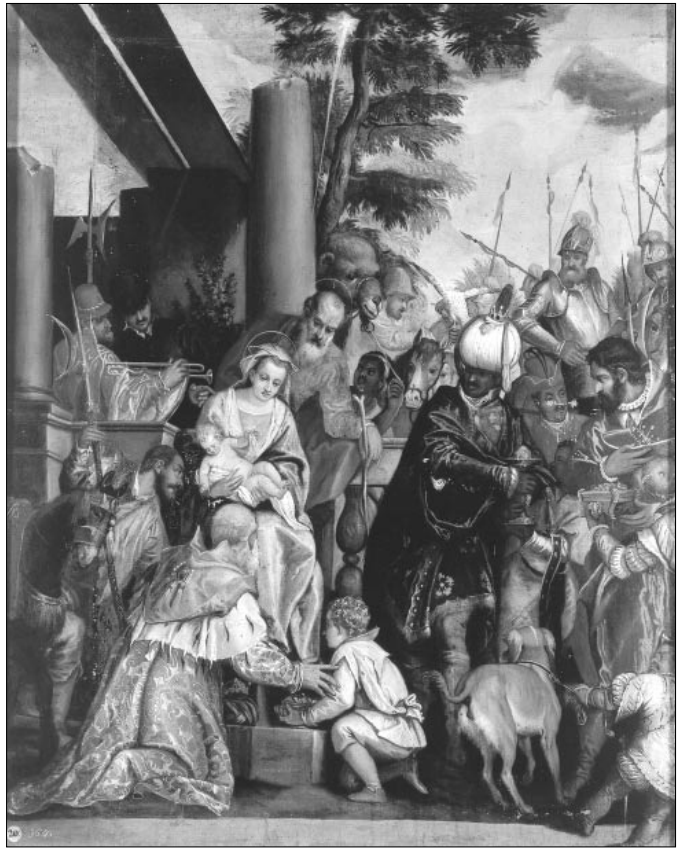

Fig. 6. Carletto Caliari: Adoración de los Reyes Magos. El Escorial (Madrid). Monasterio (Copyright Patrimonio Nacional). 
Figura en el inventario de Isabel de Farnesio de 1746 (Palacio de la Granja): "195- Una pintura original en lienzo de la escuela de Pablo Verones el niño Jesus Nuestra Señora y San Joseph en accion de adorarle de media vara y seis dedos y otro y vno de ancho (traducido a centímetros 52,55 x 43,55)". Se sigue mencionando en el inventario de dicho palacio de 1774: "195- Dos pies y medio de alto dos de ancho (traducido a centímetros 69,5 x 55, 6) Nuestra Señora con las manos juntas adorando al Niño con san Josef y un niño dicen de $=$ Pablo Verones $=$ en el dormitorio de sus Altezas $=1.500$ ". Se desconoce dónde estuvo posteriormente. No corresponde al cuadro que lleva el número 195 en el inventario de la Granja de $1789^{45}$.

También en El Escorial, se encuentra una "Adoración de los Reyes Magos" (L. 139 x 112 $\mathrm{cm})^{46}$ (fig. 6), copia de un original de Pablo Veronés conservado en la Pinacoteca di Brera de Milán ${ }^{47}$. Lo único que les diferencia en su composición se debe a los centímetros de lienzo que, como ha puesto de manifiesto Ruiz Gómez ${ }^{48}$, se añadieron al nuestro en fecha difícil de precisar y que hicieron que se desarrollara más en sus partes lateral izquierda y superior, completándose de esta manera los personajes presentes en el extremo izquierdo, añadiéndosele una columna para cerrar la escena y haciendo figurar una estrella en la parte superior. Hasta 2003, año en que se ha restaurado, se encontraba en un lamentable estado de conservación. Como es pintura que parece haber sufrido mucho en el pasado, conviene ser cautos a la hora de atribuirla. Con todo, cabría pensar que pudiera ser obra de Carletto por la fuerza gráfica de su apurado dibujo, por su cierta austeridad cromática y por la manera suelta y preciosista de raíz flamenca con la que está realizado el árbol que le sirve de fondo.

Ignoro cuándo llegó a España. Quizás sea el siguiente cuadro que el 1 de noviembre de 1809 Quilliet trasladó de El Escorial a Madrid: "Copia del VERONÉS Adoración de los Reyes" (en el cajón $\left.n^{\circ} 19\right)^{49}$. Muy posiblemente corresponde al citado por Bermejo en el Claustro Principal Alto del Monasterio: "20 (número que, sobre un papel pegado, sigue conservando en su ángulo inferior izquierdo). Los Magos ofreciendo sus dones al Niño Dios, de escuela Veneciana." ${ }^{50}$. En 1857 lo menciona Poleró en la Sala Vicarial: "CARLOS VERONÉS. 364 (número, en blanco, presente en su ángulo inferior izquierdo) Adoración de los Magos. La Virgen, sentada en las gradas de un edificio en ruinas, da á adorar el niño Dios á los Santos Reyes. Alto, 5 piés, 4 lín.; ancho, 4 piés, 1 pulg., 2 lín (traducido a centímetros 139, 8 x 113, 9).”, lugar en donde posteriormente lo verá Rotondo ${ }^{51}$.

Por último, no quisiera dejar de reseñar que en el Museo de la catedral de Oviedo se encuentra una "Piedad con angelitos" que también pudiera ser de Carletto.

Quizás sea Benedetto Caliari, hermano de Pablo, su seguidor más fiel, aunque se limitó, sin genio, a aplicar las fórmulas con él aprendidas, sin ser capaz de entender el extraordinario poder decorativo de sus composiciones, ni la fuerza y magnificencia de su colorido ${ }^{52}$.

45 "195 Otra en lienzo de quatro pies de alto, por tres de ancho, sin marco representa un Ynfante de España, en quatrocientos r.s ... 400” (Fernández-Miranda , op. cit. (nota 25), Vol. II, p. 235).

46 AA. VV. , op. cit. (nota 31), fig. 482 (reproducida como obra de Carlos Veronés). Tanto Ruiz Gómez (op. cit. (nota 5), pp. 141-142 ) como Checa (op. cit. (nota 5), p. 294) también la creen obra suya y citan además las menciones que le dedican Poleró y Rotondo.

47 L. 449 x 339 cms. Obra de polémica atribución (cf. Pignatti y Pedrocco, op. cit. (nota 9), T. II, p. 516).

48 op. cit. (nota 5), pp. 141.

${ }^{49}$ Hempel Lipschutz, op.cit. (nota 4), p. 241.

No se puede descartar que no sea el siguiente también enviado entonces: "PABLO VERONÉS Una Natividad" (en el cajón $n^{\circ}$ 53) (Hempel Lipschutz, op. cit. (nota 4), p. 246).

50 Bermejo, op. cit. (nota 4), p. 229.

51 Poleró, op. cit. (nota 4), p. 94 ( $\left.n^{\circ} 364\right)$. Rotondo, op. cit. (nota 41), p. 148 (nº 364).

52 Por lo que respecta a Benedetto Caliari, véanse Larcher Crosato, L., "Note su Benedetto Caliari", Arte Veneta, Año XXIII, 1969, pp. 115-130 e idem, op.cit. (nota 1), 1990, pp. 256-259. 
El Museo del Prado conserva un cuadro de "La Virgen y el Niño con Santa Lucía y donante, representado como San Mauricio" (L. 98 x 137) 53 (fig. 7), que muy posiblemente sea de su mano. Se trata de una "Sacra conversazione", en la que Santa Lucía presenta a un santo guerrero mártir -muy probablemente San Mauricio, ya que la cruz roja que lleva en el pecho pudiera ser el emblema de su Orden ${ }^{54}$; por otra parte, todo hace suponer que se le haya representado con los rasgos del donante, que se llamaría como él - a la Virgen y el Niño.

La crítica no concuerda en su atribución. Berenson (nota en la que figura su opinión conservada en el archivo fotográfico del Prado) pensó que se encontraba muy próxima a los cuadros juveniles de Pablo Veronés, pero que no parecía autógrafa. Heineman (misma fuente que Berenson), en visita al Museo el 17 de octubre de 1973, propuso atribuirla a Carletto Caliari. Caliari (1888) y Fiocco (1934) la creyeron de Pablo Veronés; Cocke (1977) la incluyó con dudas en su producción autógrafa. Según Pignatti (1976) se debe a Benedetto Caliari y para Pignatti y Pedrocco (1991) probable obra de este último ${ }^{55}$. En los Catálogos del Museo del Prado anteriores al de 1933 se menciona entre los cuadros de Veronés, pero ya como de autenticidad dudosa, y en el Catálogo de 1985 se atribuye a Veronés con interrogante. Por último en el inventario actualizado del Museo del Prado figura a nombre de Benedetto Caliari con interrogante, a diferencia del inventario de 1857 en donde consta como de Pablo Veronés ${ }^{56}$.

Es muy posible, como se ha dicho, que haya que atribuirla a Benedetto Caliari que, como siempre, resulta deudor de su hermano. En cuanto a su composición, pudo inspirarse en "La Virgen con el Niño, los Santos Antonio y Juan Bautista y los donantes Antonio Maria y Giambattista Marogna" (Iglesia de San Pablo, Verona), que la crítica atribuye unánimemente a éste ${ }^{57}$. Comparten ambas el situar en un plano superior (en el cuadro de Verona en lugar mucho más alto que en el madrileño) a la Virgen sujetando al Niño, éste con los brazos abiertos, y en un plano inferior a un personaje (en Madrid Santa Lucía y en Verona San Antonio) que presenta a otro (en Madrid San Mauricio, posible retrato del donante, y en Verona uno de los hermanos Marogna). A pesar de que la composición, la fisonomía de los personajes femeninos y en parte la manera suelta de manejar el pincel recuerden a Pablo, otros elementos de su ejecución parecen hablarnos de su hermano. La pincelada resulta menos segura, limpia, vibrante y viva que la de aquél. Su colorido resulta algo monótono, inexpresivo, aburrido y sin brío. Piénsese, al respecto, en el predominio de los tonos cálidos -rojo (túnica de la Virgen), naranja (túnica de Santa Lucía), rosas (manto de San Mauricio, reflejos de la túnica de la Virgen, nubes)- que no se ven ni fortalecidos ni exaltados por los colores fríos más escasos -azul (manto de la Virgen y cielo) gris (armadura de San Mauricio)-. Asimismo, la forma de acentuar la plasticidad de los pliegues (véase en particular el hinchado manto de San Mauricio) nos habla de Benedetto.

Se tiene constancia de su presencia en España desde el siglo XVII. Sin duda se trata de la siguiente pintura comprada en Inglaterra por el conde de Fuensaldaña (posiblemente durante el

\footnotetext{
53 Museo del Prado. Inventario General de Pinturas. I La Colección Real, Madrid, 1990, p. 203 , nº 719 (inv. act. $\left.\mathrm{n}^{\circ} 490\right)$.

${ }^{54}$ Louis Réau informa que la Orden militar de San Mauricio la creó la casa de Saboya en 1430 (Iconografía del arte cristiano, Iconografía de los santos, Barcelona, T. 2, Vol. 4, 1997, p. 382).

En el Catálogo de las pinturas del Museo del Prado se dice que la cruz que lleva nuestro santo es la de San Esteban, que es roja e igual en la forma a la de Malta (1985, p. 758). Por su parte Falomir (op. cit. (nota 5), pp. 152-153) piensa que es muy posible que el rostro del santo sea el de algún caballero de la orden de San Esteban (creada por Cosme de Médicis el 15 de marzo de 1562 y que tenía como misión combatir la piratería en el Mediterráneo y defender la fe católica) muerto en defensa de la fe y que adoptaría póstumamente la apariencia externa de San Jorge o de cualquier santo mártir guerrero.

55 cf. Pignatti y Pedrocco, op. cit. (nota 9), T. II, p. 515. Véanse, también, Checa, op. cit. (nota 5), p. 292 (Pablo Veronés) y Falomir, op. cit. (nota 5), pp. 152-153 (Paolo Caliari, "El Veronés" (?)).

56 Museo del Prado. Inventario General de Pinturas I La Colección Real, Madrid, 1990, p. 203.

57 Véase Pigatti y Pedrocco, op. cit. (nota 9), T. I, p. 253.
} 
año de 1651) y enviada a España: "Mas otra pieca de nra Sra. con santa Margarita y San Jorge de mano de Pablo Veroneus fs. 1500"58. Poco después debió pasar a manos de la corona, ya que se cita en el inventario del Alcázar de Madrid de 1666 en el "Pasillo del medio-dia": "633- vara y media de largo vara y quarta de ancho (traducido a centímetros 104,5 x 125,25) vn Nra. Sra. con el Niño Santa Lucia y S. Jorge de mano de Pablo Verones en 200 dus" y, posteriormente, en el de 1686 en la Galería del Mediodía: "Otra de vara y media de ancho y vara y quarta de alto de nra señora el niño, Sn Joseph, y Sta Lucia con vnas Palmas de mano de Pablo Verones"59, en donde seguirá figurando, con el número 79, en el de $1700^{60}$. En el inventario del Palacio Real de 1789 se menciona entre las "Pinturas descolgadas en Palacio": "973 (número que, en blanco, todavía conserva en su ángulo inferior izquierdo) Siete quartas de largo, y vara y quarta de alto (traducido a centímetros 104,5 x 147). La Virgen con el niño, S.n Jorge y S.ta Lucia. Pablo Veronès ....4.000"61.

Desgraciadamente se encuentra en muy mal estado de conservación. Ha sufrido mucho y perdido en algunas partes capas de pintura. Obsérvese al respecto que prácticamente no se pueden apreciar los pliegues del manto y túnica de la Virgen de la cintura para abajo, que la mano derecha de Santa Lucía no es más que un muñón informe, que el dibujo del brocado de la cortina colocada detrás de la Virgen sólo se aprecia en algunas partes. Si se coteja la situación del cuadro en la actualidad con la que refleja una foto antigua conservada en el archivo del Museo del Prado (realizada entre 1872 y 1907, años en que constaba en los catálogos con el número 531 que aparece en la fotografía), se puede deducir que, aunque no se pueda excluir que desde entonces no se haya limpiado, sí se puede afirmar que de ningún modo ha sido sometido a una importante restauración.

En el Palacio Arzobispal de Madrid existe una "Flagelación" (L. 133 x 113) (fig. 8), depósito del Museo del Prado ${ }^{62}$, que también pudiera ser obra suya. Se ha atribuido con dudas a Palma el Joven. Cierto es que, por lo que se refiere a su composición, la postura de los sayones que azotan a Cristo resulta muy semejante a la de los mismos personajes del cuadro homónimo de Palma el joven conservado en el Museo de Bellas Artes de Lyon ${ }^{63}$, aunque no deja de ser menos cierto que, muy probablemente, en ambos casos sirvieran de inspiración las figuras correspondientes de la "Flagelación" de Sebastiano del Piombo (Iglesia de San Pietro in Montorio, Roma), obra basada en un dibujo de Miguel Angel ${ }^{64}$ y que pudieron conocer ambos pintores a través del grabado de Adamo Ghisi65. Sin embargo, por lo que respecta tanto a la fisonomía de los personajes como al estilo con el que está realizado pertenece nuestro cuadro a la esfera de Pablo Veronés. Sin duda tiene en dicho pintor origen el rostro de Cristo de pequeña y regular nariz, bigote caído y corta

\footnotetext{
58 Vergara, A., "The Count of Fuensaldaña and David Teniers: their purchases in London after the civil war", The Burlington Magazine, $\mathrm{n}^{\circ}$ 1.031, febrero de 1989, p. 132.

59 cf. Bottineau ( op.cit. (nota 23), T. LX, $\mathrm{n}^{\circ} 2,1958$, p. 155), quien identifica este asiento con nuestra pintura y da correcta noticia de su presencia en los inventarios del Alcázar de 1666 y 1700.

${ }^{60}$ Fernández Bayton, op. cit. (nota 24), Vol. I, p. 26.

61 Fernández-Miranda, op. cit. (nota 25), Vol. I, p. 63.

62 Depositado por R. O., desde 1887. Procede del Museo de la Trinidad (Museo del Prado. Inventario General de Pinturas. II El Museo de la Trinidad (Bienes desamortizados), Madrid, 1991, p. 238, $\mathrm{n}^{\circ} 771$ (inv. act. $\mathrm{n}^{\circ}$ 3.517) (en la ficha del inventario actualizado figura como "Anónimo veneciano del s. XVII. PALMA EL JOVEN (?)" y en la ficha del inventario de la Trinidad no se atribuye). Se menciona como "Anónimo veneciano S. XVI" en Espinós, A., Orihuela, M., y Royo Villanova, M., “"El Prado disperso". Cuadros depositados en Madrid. II”, Boletín del Museo del Prado, $\mathrm{n}^{\mathrm{o}} 2,1980, \mathrm{p} .105$.

63 Véase Mason Rinaldi, S. (Palma il Giovane. L'opera completa, Milán, 1984, p. 90 y fig. 135), quien la considera de hacia 1592.

64 Véase Hirst, M., Sebastiano del Piombo, Oxford, 1981, pp. 49-65.

65 The Illustrated Bartsch, Nueva York, Vol. 31 (ant. 15 (parte 4)), 1986, pp. 154 y 155 (se reproduce el original de Ghisi y una copia).
} 


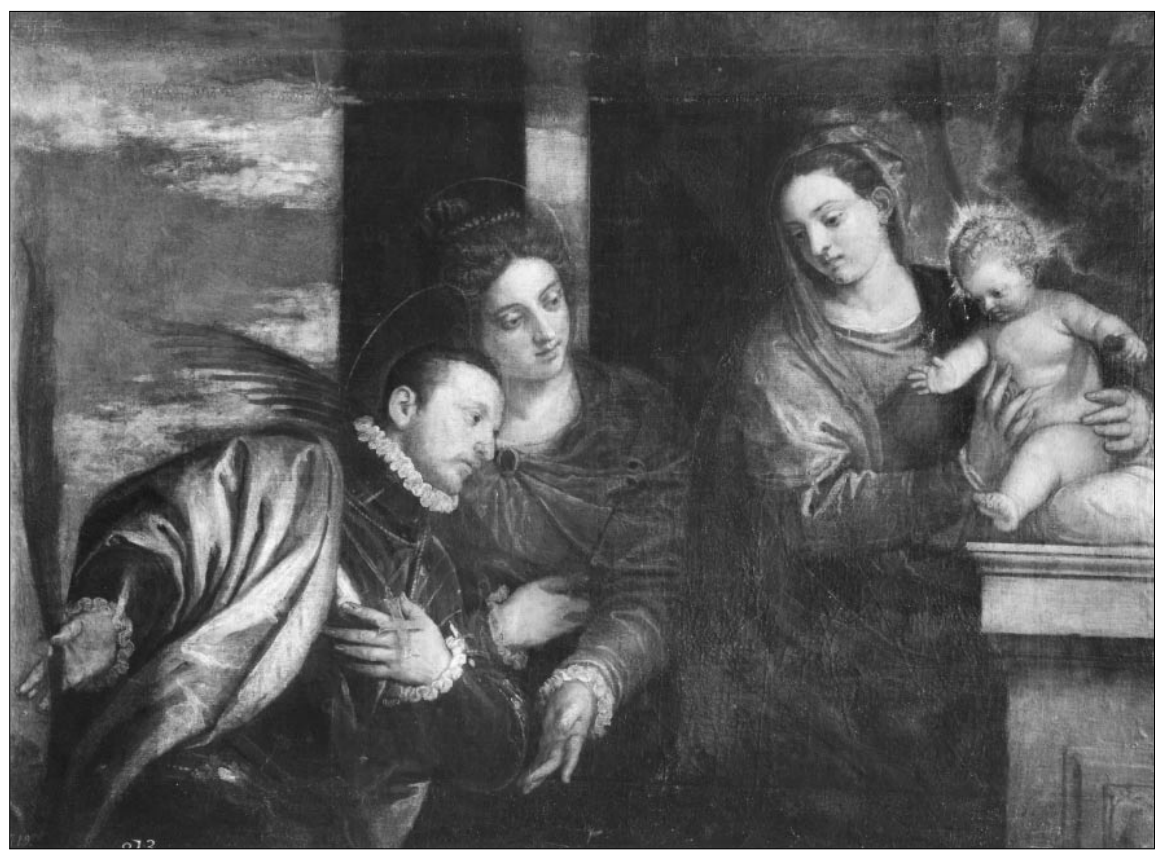

Fig. 7. Benedetto Caliari: La Virgen y el Niño con Santa Lucía y donante representado como San Mauricio. Madrid. Museo del Prado.

Fig. 8. Benedetto Caliari: Flagelación. Madrid. Museo del Prado. Cuadro depositado en el Palacio Arzobispal de Madrid.

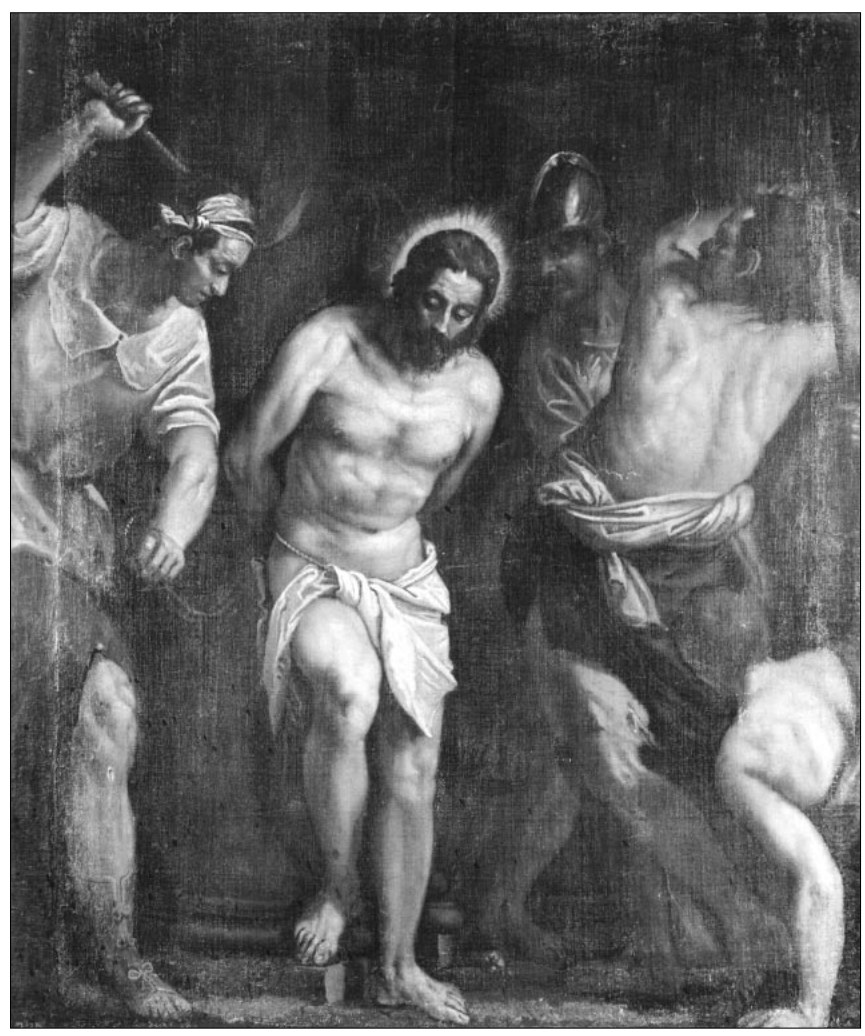

AEA, LXXIX, 313, ENERO-MARZO, 43-60, 2006, ISSN: 0004-0428 
barba, así como su hercúleo cuerpo de anchos y altos hombros, piénsese al respecto en el "Cristo muerto sostenido por la Virgen y un Angel" del Ermitage de San Petesburgo ${ }^{66}$. En cuanto al paño de pureza sostenido por una cuerda, también lo utilizó Veronés en su "Cristo crucificado con la Virgen y San Juan" (iglesia de San Lazzaro dei Mendicanti de Venecia) ${ }^{67}$. Asimismo, de los sayones, el que se encuentra detrás de Cristo a su izquierda lleva un casco muy semejante al del mismo personaje situado en el mismo lugar en el cuadro "Cristo escarnecido y fustigado" (Young Memorial Museum, San Francisco) ${ }^{68}$. A pesar de estas coincidencias con obras del maestro, falta en nuestra pintura el cadencioso ritmo que sabe infundir éste a sus obras, así como la opulencia y suntuosidad de sus amplias y seguras pinceladas. Aunque no es pobre en su colorido -obsérvese el amarillo intenso de la camisa del sayón a la derecha de Cristo o el cálido rojo de la del que lleva casco-, carece del refinado gusto para combinar los colores del que siempre dió muestras Pablo. Además, nos hacen pensar en Benedetto tanto el cierto carácter algo mazacote y pesado de sus personajes como la fidelidad por seguir modelos del maestro sin ser capaz de alcanzar su grandeza. Asimismo, creo percibir afinidades entre nuestra pintura y otras de Benedetto. Los esbirros con sus tipos toscos y cuadrados recuerdan a las personajes de la "Huida de los Hebreos" (Museo de Caen) que Larcher Crosato atribuye a Benedetto. En cuanto a sus manos anchas y gruesas son muy semejantes a las de las figuras de la "Cena y el Lavatorio de los pies" (Iglesia de San Giovanni e Paolo, Venecia) que ya Boschini (1664) atribuyera al mismo Benedetto. Además la postura del esbirro agachado dando la espalda de nuestro cuadro resulta muy semejante a la del apóstol de espaldas y arrodillado en primer término del mencionado cuadro veneciano 69 .

Por último, en las Salas Capitulares de El Escorial se conserva un cuadro del encuentro de "Jesús y la Samaritana" (Lienzo 98 x 137 cms) (fig. 9), que posiblemente también le pertenezca. Como ha sido puesto de manifiesto por Ruiz Gómez ${ }^{70}$, su composición guarda una estrecha relación con la de la obra homónima conservada en el Kunsthistorisches Museum de Viena ${ }^{71}$. Sin embargo, se diferencian lo suficiente para que se pueda pensar que son de distinta mano. Mientras que la composición vienesa resulta clara y elegantemente espaciosa, al haberse dispuesto la escena principal en un primerísimo plano frente a un paisaje bajo que la encuadra sin desviar la atención del espectador, la de la pintura escurialense resulta mucho más abigarrada y confusa, debido al paisaje alto con arquitecturas que le sirve de fondo y contra el que parecen estampadas las figuras. Por otra parte, los personajes presentes en el cuadro de El Escorial no participan del canon airosamente estilizado de los de la pintura de Viena. De los discípulos de Veronés posiblemente sea a Benedetto, como se ha dicho, a quien deba atribuírsele. La cierta torpeza señalada en su composición, así como la falta en sus figuras de la exquisita gracia del maestro parece hablarnos de él. También parece hacerlo tanto la pincelada, que en algunas partes resulta algo vacilante y confusa, como la tendencia a acentuar las zonas oscuras de los paños, lo que origina su aspecto algo hinchado, y la falta de fuerza expresiva del color ocre de la túnica de la Samaritana, que en absoluto la hace resaltar del paisaje.

\footnotetext{
66 Véase Pignatti y Pedrocco, op. cit. (nota 9), T. II, pp. 405-406.

67 Véase Pignatti y Pedrocco, op. cit. (nota 9), T. I, pp. 391-393.

68 En la actualidad la crítica tiende a considerarlo en su totalidad de Pablo Veronés (véase Pigatti y Pedrocco, op. cit. (nota 9), T. II, pp. 496-497).

69 Por lo que respecta a estas obras, véase Larcher Crosato, op. cit. (nota 52), 1969, pp. 117-118 y 122-123.

70 Ruiz Gómez (op. cit. (nota 5), pp. pp. 139-140), quien la considera de Pablo Veronés. Checa (op. cit. (nota 5), p. 293) la recoge entre las obras de Pablo Veronés; y en AA. VV. , op. cit. (nota 31), fig. 407 se reproduce como "Atribuida al Veronés".

${ }^{71}$ Cuadro que en el pasado se llegó a pensar que no era obra de Pablo Veronés, pero que actualmente la crítica está de acuerdo en que le pertenece (véase Pignatti y Pedrocco, op. cit. (nota 9), T. II, pp. 466-467).
} 


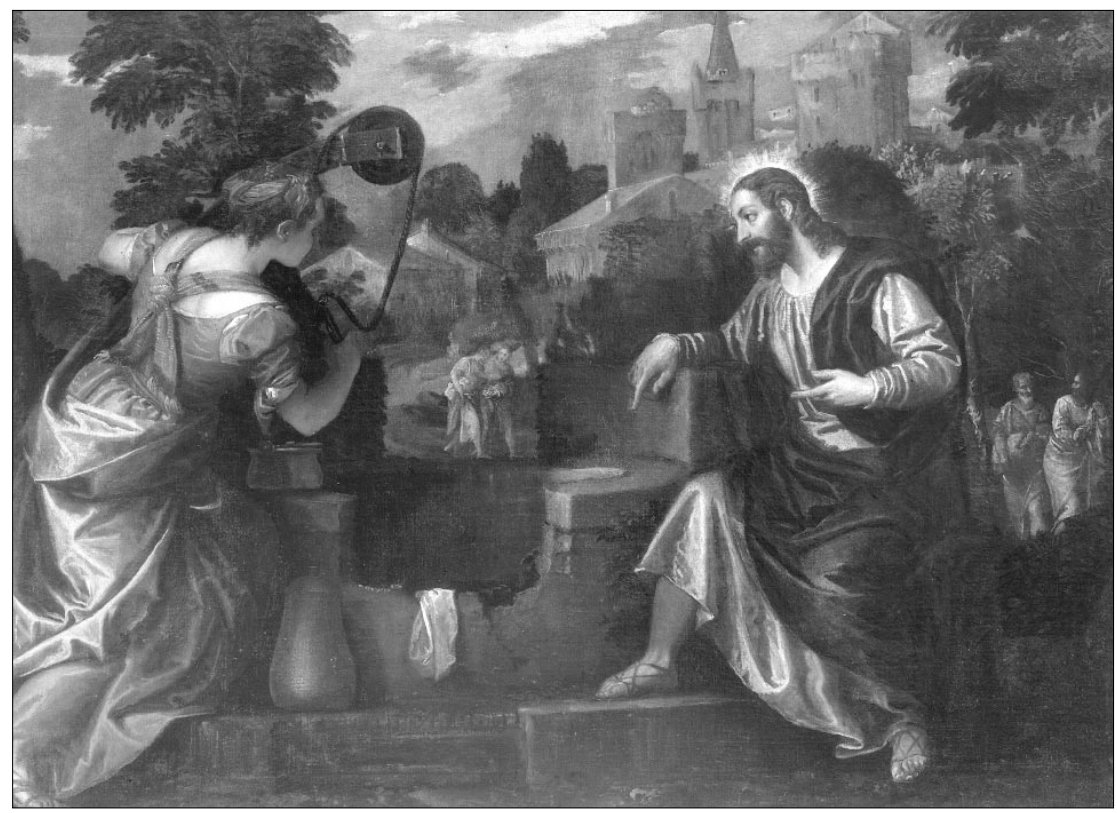

Fig. 9. Benedetto Caliari: Jesús y la samaritana. El Escorial (Madrid). Monasterio (Copyright Patrimonio Nacional).

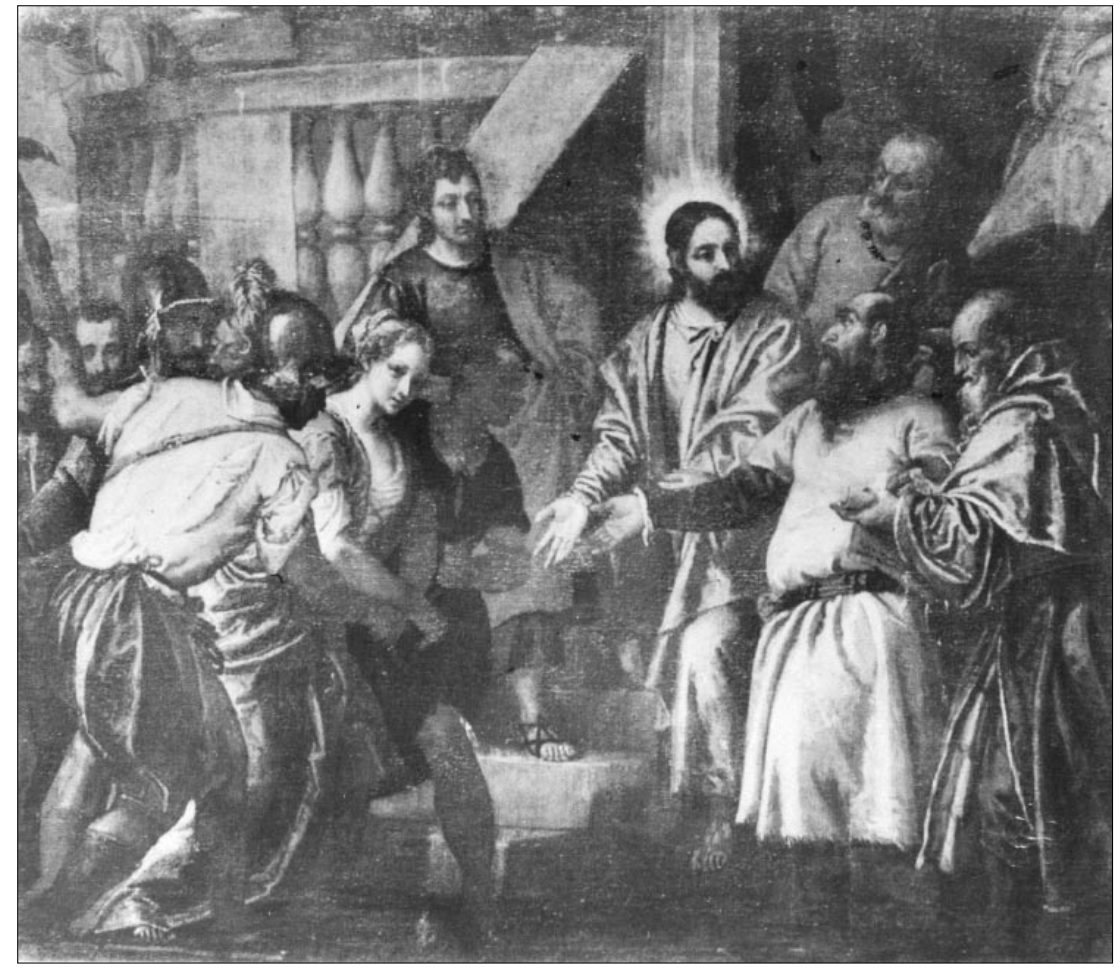

Fig. 10. Benedetto Caliari (?): El encuentro de Cristo y la mujer adúltera. Madrid. Museo del Prado. Cuadro depositado en la Casa-Museo Colón de Las Palmas de Gran Canaria. 
Gracias a Poleró se sabe que formó parte de la colección que Carlos IV tenía en su galería de San Alejo en el monte Aventino, en Roma ${ }^{72}$, lo que viene a confirmar su presencia en el inventario de los cuadros de dicho monarca enviados de Roma tras su muerte: "271. El Señor con la Samaritana por Pablo Verones, alto 3.p. ancho 4 p. 2.p. Bueno"73. Afortunadamente su estado de conservación es satisfactorio.

De la familia Caliari es el hijo mayor de Pablo, Gabriele, el pintor que, a juzgar por lo poco que de él se conoce, debía ser el menos dotado. Por el momento, únicamente disponemos de una obra por él firmada, "El Padre Eterno que desde el cielo contempla a Santa Ana con la Virgen y a los lados dos ángeles" (Iglesia parroquial, Liettoli), y de una réplica de su parte central, conservada en los Museos Capitolinos de Roma, que Crosato Larcher le atribuye ${ }^{74}$.

Con todas las reservas a que obliga el hecho de conocerlo sólo a través de una fotografía, muy probablemente es a él a quien habrá que atribuir "El encuentro de Cristo y la mujer adúltera" (L. 103 x 118 ) (fig. 10), deposito del Museo del Prado, que se conserva en la Casa-Museo Colón de Las Palmas de Gran Canaria ${ }^{75}$.

Aunque sea obra que deba mucho a Pablo Veronés, no puede, sin embargo, considerarse de su mano. Su composición resulta abigarrada y torpe; sus figuras, de formas cuadradas y de movimientos mecánicos, carecen de gracia y de elegancia. Por otra parte, la falta de armonía en la disposición de la escena, el aspecto macizo de sus personajes y los pliegues amplios y rectilíneos de sus vestiduras hacen recordar la pintura segura de Gabriele de la iglesia parroquial de Liettoli. Además se sabe por Ridolfi que éste pintó un cuadro del mismo asunto, que, aunque no haya elementos que lo confirmen, pudiera tratarse del nuestro: "Fece anco vn studioso quadro dell'Adultera..."76.

En 1657 el Padre Santos la cita en el Atrio de los Capítulos de El Escorial, informándonos además de que la donó al monasterio Felipe IV: "Otro ay de Paulo Veronès, que es la Historia de la Mujer Adultera, de lo marauilloso que hizo este Autor....”. En 1667 ya se encontraba en el Capítulo del Prior, en donde seguirá citándose en las sucesivas ediciones del libro del Padre Santos de 1681 y $1698^{77}$, en una relación anónima del siglo XVII sobre los cuadros de El Escorial ${ }^{78}$, y en

72 Poleró, op. cit. (nota 4), p. 122-123, nota a pie de página 1; en la p. 127 se cataloga, como obra de Pablo Veronés, asignándole el número 549 (número que en color blanco sigue figurando en su ángulo inferior izquierdo).

73 Legajo $\mathrm{n}^{\circ}$ 811, p. 23 (Documento fechado el 11 de febrero de 1819 y conservado en el Ministerio de Asuntos Exteriores).

A. Perera cita entre los cuadros enviados de Roma a la muerte de Carlos IV uno de "Jesús y la Samaritana" de Veronés, sin relacionarlo sin embargo con el nuestro ("Carlos IV "Mecenas y coleccionista de obras de arte"”, Arte Español,, tomo XXII, 1958-1959, p. 28).

74 Sobre este pintor, véanse Crosato Larcher, L., "Per Gabriele Caliari”, Arte Veneta, Año XVIII, 1964, pp. 174 175 y Larcher Crosato, op. cit. (nota 1), 1990, pp. 262-263.

75 Depositado por O.M. desde 1940 (Museo del Prado. Inventario General de Pinturas. I La Colección Real, Madrid, 1990, p. 131, nº 433 (inv. act. $\mathrm{n}^{\circ} 495$ ).

Tanto Madrazo (1872) como Caliari (1888) y Meissner (1897) la atribuyeron a Pablo Veronés (apud Pignatti - op. cit. (nota 21), T. I, p. 187 y T. II, fig. 838- quien, aunque la considera más bien obra de taller, no creyó sin embargo aceptables las atribuciones a Farinati o a Zelotti recogidas por Madrazo), autor a nombre de quien también la citaron Gaya Nuño (op. cit. (nota 17), T. LVIII, 1954, p. 117 y op. cit. (nota 17), 1968, p. 634) y el autor del inventario del Museo del Prado de 1857. Ultimamente, Ruiz Gómez (op. cit (nota 5), p. 137-138) -quien realiza un buen estudio de su procedencia, aunque se equivoca al decir que Ximénez (1764) la menciona en el Capítulo Vicarial- sigue pensando que pertenece al maestro; por el contrario en el Museo del Prado. Inventario General de Pinturas. I La Colección Real (ficha actualizada) se dice del taller de Veronés, opinión compartida por Checa (op. cit. (nota 5), p. 295-296). Por último, figura como anónimo veneciano del siglo XVI en "'El Prado disperso": cuadros depositados en Las Palmas de Gran Canaria", Boletín del Museo del Prado, tomo XIII, n 31, 1992, p. 86.

${ }^{76}$ Ridolfi, C., Le Meraviglie dell'Arte. Ovvero le vite degli Illustri Pittori veneti e dello Stato, Venecia, Parte I, 1648, p. 346.

77 Santos, op. cit. (nota 4), 1657, fol. 69v (en realidad debía ser el fol. 65v). Idem, idem, edición de 1667, fol. 75v. Idem. idem, edición de 1681, fol. 62v. Idem, idem, edición de 1698 (apud. Sánchez Cantón, F. J., Fuentes literarias para la Historia del Arte Español, Madrid, T. II, 1933, p. 300).

78 Andrés, op.cit. (nota 4), p. 53. 
el siglo XVIII,siempre como obra de Pablo Veronés, en los escritos de Ximénez y Ponz ${ }^{79}$. El 1 de noviembre de 1809 figura entre los cuadros trasladados por Quilliet de El Escorial a Madrid: "Núm. 20 (cajón, se entiende) contiene:... VERONÉS La mujer adúltera." 80 . De vuelta al Monasterio, Bermejo la menciona en la sacristía: " 25 . La historia de la muger adúltera con figuras pequeñas, por Pablo Veronés." 81. En 1839 ingresó en el Museo del Prado. $395)$.

79 Ximénez, op. cit. (nota 4), fol. 93. Ponz, op. cit (nota 4), 1788, T. II, Carta IV, nº 48 (Madrid, 1988, Vol. 1, p.

${ }^{80}$ Hempel Lipschutz, op. cit. (nota 4), p. 242.

${ }^{81}$ Bermejo, op. cit. (nota 4), p. 90. 